\title{
Transanal Minimally-Invasive Surgery (TAMIS): Experience with No Closure of the Rectal Defect
}

\author{
Diego Naiderman ${ }^{1,3,4}$ Ana Laura Tufare ${ }^{2(0)}$ Lady Beatriz Trinchero ${ }^{30}$ Fernando Rossi ${ }^{40}$ \\ Martín Dolan ${ }^{3 \odot ~ D i e g o ~ M a r t i ́ n ~ C a n o ~}{ }^{1 \odot}$ Rafael López Fagalde ${ }^{3 \odot}$ Gastón Leonardo Jury ${ }^{3 \odot}$ \\ ${ }^{1}$ Coloproctology Sector, Hospital Interzonal General de Agudos "Dr. \\ Oscar E. Alende” (HIGA), Mar del Plata, Buenos Aires, Argentina \\ 2 Universidad Nacional de Mar del Plata, Mar del Plata, Buenos Aires, \\ Argentina \\ ${ }^{3}$ Centro de Estudios Digestivos, Mar del Plata, Buenos Aires, \\ Argentina \\ ${ }^{4}$ Clínica Pueyrredón, Mar del Plata, Buenos Aires, Argentina \\ Address for correspondence Diego Naiderman, MD, Hospital \\ Interzonal General de Agudos “Dr. Oscar E. Alende”, Av. Juan B. Justo \\ 6.701, Mar del Plata, Buenos Aires, 7600, Argentina \\ (e-mail: naidermand@hotmail.com). \\ J Coloproctol 2021;41(4):348-354.
}

\begin{abstract}
Background In transanal minimally-invasive surgery (TAMIS), the closure of the rectal defect is controversial, and endoluminal suture is one of the most challenging aspects. The goal of the present study is to evaluate the short- and medium-term complications of a consecutive series of patients with extraperitoneal rectal injuries who underwent TAMIS without closure of the rectal defect.

Materials and Methods A prospective, longitudinal, descriptive study conducted between August 2013 and July 2019 in which all patients with extraperitoneal rectal lesions, who were operated on using the TAMIS technique, were consecutively included. The lesions were: benign lesions $\geq 3 \mathrm{~cm}$; neuroendocrine tumors $\leq 2 \mathrm{~cm}$; adenocarcinomas in stage T1N0; and adenocarcinomas in stage T2N0, with high surgical risk, or with the patients reluctant to undergo radical surgery, and others with doubts about complete remission after the neoadjuvant therapy. Bleeding, infectious complications, rectal stenosis, perforations, and death were evaluated.

Results A total of 35 patients were treated using TAMIS without closure of the defect. The average size of the lesions was of $3.68 \pm 2.1 \mathrm{~cm}$ ( $95 \%$ confidence interval [ $95 \% \mathrm{Cl}]: 0.7 \mathrm{~cm}$ to $9 \mathrm{~cm}$ ), their average distance from the anal margin was of $5.7 \pm 1.48 \mathrm{~cm}$, and the average operative time was of $39.2 \pm 20.5$ minutes, with a minimum postoperative follow-up of 1 year. As for the pathologies, they were: 15 adenomas; 3 carcinoid tumors; and 17 adenocarcinomas. In all cases, the rectal defect was left open.

\section{Keywords}

- TAMIS

- transanal surgery

- closure

- rectal defect

- complications

The overall morbidity was of $14.2 \%$. Two patients (grade II in the Clavien-Dindo classification) were readmitted for pain treatment, and three patients (grade III in the Clavien-Dindo classification) were assisted due to postoperative bleeding, one of whom required reoperation.

Conclusion The TAMIS technique without closure of the rectal defect yields good results, and present a high feasibility and low complication rate.
\end{abstract}

received

December 22, 2020

accepted after revision

March 22, 2021
DOI https://doi.org/

$10.1055 / \mathrm{s}-0041-1735642$.

ISSN 2237-9363.

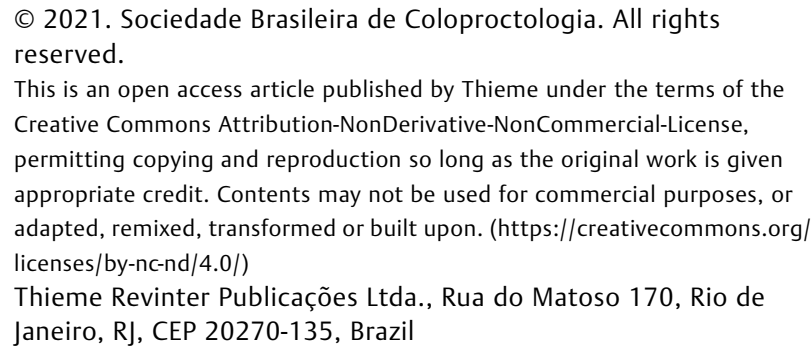

(C) 2021. Sociedade Brasileira de Coloproctologia. All rights reserved.

This is an open access article published by Thieme under the terms of the Creative Commons Attribution-NonDerivative-NonCommercial-License, permitting copying and reproduction so long as the original work is given appropriate credit. Contents may not be used for commercial purposes, or adapted, remixed, transformed or built upon. (https://creativecommons.org/ licenses/by-nc-nd/4.0/)

Thieme Revinter Publicações Ltda., Rua do Matoso 170, Rio de Janeiro, RJ, CEP 20270-135, Brazil 


\section{Introduction}

Abdominal rectal resection combined with total mesorectal excision remains the gold standard treatment for rectal cancer. ${ }^{1,2}$ However, the postoperative morbidity is high, and functional sequelae are common, requiring a permanent stoma in $10 \%$ to $30 \%$ of the patients. ${ }^{3-5}$

Benign and malignant tumors of the lower rectum in the initial stages have traditionally been managed with local excision using the Parks technique. However, this approach has limitations in terms of exposure and visibility of the rectal lumen. ${ }^{6}$ In 1985, Buess et al. ${ }^{7}$ described the transanal endoscopic surgery (TEM), which was established as the treatment of choice for early-stage benign and malignant rectal tumors not suitable for resection with the Parks technique or flexible endoscopy. ${ }^{8,9}$ However, several factors have prevented this technique from becoming popular, such as the need for high-cost special instruments and a long learning curve. ${ }^{10,11}$

Transanal minimally-invasive surgery (TAMIS), described by Atallah et al. ${ }^{12}$ in 2013 , overcame these limitations with the use of a flexible transanal device and standard laparoscopic instruments, and results similar to those of TEM. ${ }^{13,14}$ This technique is especially useful in extraperitoneal rectal injuries that are difficult to access via the former approach.

Currently, closure of the rectal defect below the peritoneal reflection is still controversial, and colorectal surgeons have not reached a common ground regarding it. ${ }^{15}$ Endoluminal suturing, which can take longer than the dissection itself, is one of the most challenging aspects of the procedure. Likewise, the inability to suture through the platform has been a barrier for the adoption of this technique. ${ }^{16-18}$ The literature is discordant regarding the closure of the rectal wound, and it is difficult to come to conclusions due to the heterogeneity of the studies. ${ }^{15,19}$

Our objective was to carry out a descriptive study of a consecutive series of patients with extraperitoneal rectal lesions who underwent TAMIS without closure of the rectal defect, evaluating the occurrence of complications in the short and medium terms.

\section{Materials and Methods}

The present is a descriptive, prospective and longitudinal study. Between August 2013 and July 2019, all patients with extraperitoneal rectal lesions and operated using the TAMIS technique were consecutively admitted to two private and one public institutions in the city of Mar del Plata, Argentina. They presented the following lesions: benign lesions $\geq 3 \mathrm{~cm}$ of difficult endoscopic resolution, neuroendocrine tumors $\leq 2 \mathrm{~cm}$, stage T1N0 adenocarcinomas without histological signs of poor prognosis, stage T2NO adenocarcinomas of high surgical risk or with refusal on the part of the patient to undergo radical surgery, or with patients with doubts about complete remission after the neoadjuvant treatment.

Preoperative staging was performed with rectal digital examination, flexible videocolonoscopy, high-resolution abdominal and pelvic magnetic resonance imaging (MRI), chest computed tomography (CT), and an assessment of the levels of carcinoembryonic antigen (CEA) in malignant lesions. In the cases in which the neoadjuvant treatment was performed, restaging was performed between 6 and 8 weeks after the end of the treatment.

All procedures were performed by the same surgeon. Colonic preparation with phosphates and general and/or spinal anesthesia was performed. Antibiotic prophylaxis with metronidazole and gentamicin was administered and supplemented, in most cases, with oral amoxicillinclavulanic acid for five days after discharge.

For the present series, we used the Sils (Covidien, Mansfield, MA, United States) multiple access port or the GelPOINT (Applied Medical, Rancho Santa Margarita, CA, United States) path transanal access platform, $\mathrm{CO} 2$ insufflation pressure of $15 \mathrm{~mm} \mathrm{Hg}$, standard laparoscopic instruments, and a harmonic scalpel (UltraCision, Ethicon Endosurgery, Inc. Cincinnati, $\mathrm{OH}$, United States).

The lithotomy position was used. After placing the transanal device, the resection margins were marked with electrocautery. The incisions were deepened up to the perirectal fat, the resections were completed in a proximal direction, and an exhaustive control of hemostasis was performed. The surgical wound was left open in all patients, regardless of the size of the lesion or its location.

The minimum postoperative follow-up was of 1 year, and we recorded the occurrence of the following events which were considered postoperative complications: rectal bleeding; infection (defined by at least 2 of the following parameters: fever $>38.5^{\circ} \mathrm{C}$;, rectal pain; leukocytosis $>110$ cells $/ \mathrm{L}{ }^{9}$ images compatible with perirectal collection; or clinical diagnosis of infection); postoperative stenosis requiring some type of dilation; perforation into the abdominal cavity; and death.

The results were expressed as means and standard deviations (SDs), ranges or percentages, according to the type of variable analyzed.

\section{Results}

In a period of 6 years, 35 patients were treated with the TAMIS technique without closure of the rectal defect. There were 18 (51.4\%) female patients, with an average age of $61 \pm 12$ (range: 30 to 86 ) years. The mean size of the lesions was of $3.68 \pm 2.1$ (range: 0.7 to 9) $\mathrm{cm}$, and the mean distance from the anal margin to the lesion was of $5.7 \pm 1.48$ (range: 3 to 8.5 ) $\mathrm{cm}$. General anesthesia was administered to 4 patients, general anesthesia + spinal anesthesia, to 9 , and only spinal anesthesia, to 22 . The operative time was of $39.2 \pm 20.5$ minutes (range: 17 to 90 minutes), and the hospitalization time was of $1.375 \pm 1.175$ days (range: 1 to 7 days) (-Table $\mathbf{1}$ ).

The pathological anatomy was as follows: 15 adenomas (43\%), 3 carcinoid tumors (8\%), and 17 adenocarcinomas (49\%). There was 1 patient with ypT0 who underwent preoperative chemoradiotherapy (CRT) and the scar was resected to confirm complete remission, 4 patients with carcinomas in situ, 4 with T1 tumors, and 8 with T2 tumors ( - Table 1). Out of the patients with T2 tumors, 1 underwent adenoma biopsies, 3 refused radical surgery, and 4 were 
Table 1 Characteristics of the study sample

\begin{tabular}{|l|l|}
\hline Patients (n) & 35 \\
\hline Female gender: n (\%) & $18(51.4 \%)$ \\
\hline Age (years) & $61 \pm 12$ \\
\hline Lesion size: standard deviation (cm) & $3.68 \pm 2.1$ \\
\hline $\begin{array}{l}\text { Distance to anal margin: standard } \\
\text { deviation (cm) }\end{array}$ & $5.7 \pm 1.48$ \\
\hline $\begin{array}{l}\text { Surgical time: standard deviation } \\
\text { (minutes) }\end{array}$ & $39.2 \pm 20.5$ \\
\hline $\begin{array}{l}\text { Hospitalization time: standard } \\
\text { deviation (hours) }\end{array}$ & $33 \pm 28.2$ \\
\hline Pathological anatomy (n) & 15 \\
\hline - Adenomas & 3 \\
\hline - Carcinoid tumor & 1 \\
\hline - T0 Carcinoma & 4 \\
\hline - Tis Carcinoma & 4 \\
\hline - T1 Carcinoma & 8 \\
\hline - T2 Carcinoma & \\
\hline
\end{tabular}

substaged by MRI, completing the treatment in 2 of them with the Miles operation. From the series, 5 were submitted to neoadjuvant therapy.

There was no mortality in the series, and the global morbidity was of $14.2 \%$ (5 patients) (-Table 2 ). In total, 2 $(5,7 \%)$ patients who had undergone neoadjuvant therapy were re-admitted for pain management (Clavien-Dindo II); 3 patients (8.5\%) had postoperative bleeding: 1 patient had self-limited bleeding on the eighth day after surgery (Clavien-Dindo I), 1 patient required transfusion with 2 units of red blood cells (Clavien-Dindo II), and only 1 required re-intervention (Clavien-Dindo III), and they represented $2.8 \%$ of the cases ( - Table 3 ). There were no infectious complications, rectal stenosis, or perforations into the abdominal cavity.

\section{Discussion}

The performance of transanal excision of rectal lesions has radically changed with TEM; ${ }^{20}$ however, several factors have prevented this technique from becoming popular. ${ }^{10,11}$ In Certain aspects, such as surgical time and anal sphincter dysfunction, similar or even better results are achieved with TAMIS than with TEM. ${ }^{13,21,22}$ The patient is always placed in the lithotomy position regardless of the location of the injury, which enables a quick abdominal approach, if necessary.

Table 2 Numbers and percentages of complications observed in the series

\begin{tabular}{|l|}
\hline Postoperative pain: $2(5.7 \%)$ \\
\hline Bleeding: $3(8.5 \%)$ \\
\hline Total: $5(14.2 \%)$ \\
\hline
\end{tabular}

Table 3 Complications according to the Clavien-Dindo classification

\begin{tabular}{|l|l|l|l|}
\hline & Grade I & Grade II & Grade III \\
\hline Percentage (\%) & 2.8 & 8.5 & 2.8 \\
\hline Postoperative pain (n) & 0 & 2 & 0 \\
\hline Bleeding (n) & 1 & 1 & 1 \\
\hline
\end{tabular}

These advantages, together with the lower cost and the shorter learning curve, have lead more surgeons to adopt the minimally-invasive transanal resection techniques. ${ }^{23,24}$

In the present series, all resections were performed with a full-thickness excision of the rectal wall. This is mandatory in malignant lesions and highly recommended in benign ones as well, since the piece excised may contain an invasive component, which is likely to occur in up to $30 \%$ of the cases. $^{25,26}$

In total, four patients were understaged by MRI, and 3 of them had undergone neoadjuvant therapy, showing the difficulty in evaluating these lesions. Although transanal ultrasound has demonstrated its value in the differentiation between $\mathrm{T} 1$ and $\mathrm{T} 2$ tumors, we use high-resolution MRI with rectal-specific protocols, which, in recent years, has at least matched transanal ultrasound in the staging of early tumors. Among its advantages, it is able to assess poor prognostic factors for local resection and enables the re-staging of the lesions after neoadjuvant treatment. ${ }^{27-30}$

Despite efforts to standardize the technique in minimallyinvasive transanal resections, ${ }^{31,32}$ the closure of the rectal defect remains one of the most controversial points, ${ }^{20}$ especially below the peritoneal reflection, in which there is a lower risk of perforation into the peritoneal cavity. ${ }^{15}$ The benefits of the closure of rectal defects are not well established. This is because the rectum and mesorectum are wellvascularized tissues that provide an excellent means for healing the rectal wall as well as a barrier to infection. ${ }^{33}$ Suturing the defect is technically difficult, since not only the space is very small and it is hard to face the edges to be sutured without tension, but also it is time consuming, even longer than the dissection itself, doubling the time of the intervention. ${ }^{18-20}$ Different types of sutures have been used, such as continuous intracorporeal suturing, separate stitches, extracorporeal knots, and metal clips; ${ }^{16,18,33-35}$ even so, $30 \%$ of the defects cannot be closed. ${ }^{20}$

The reports are contradictory, not only in comparative studies and randomized studies, but also in meta-analyses, in which, in most cases, there are no statistically significant differences in the complications of those who leave the defects open and those who close them. Hahnloser et al. ${ }^{20}$ found no significant differences in postoperative complications (bleeding or infection); yet, Brown et al., ${ }^{16,20}$ found out that, in patients in whom the defect was closed after TEM, there were fewer complications and fewer readmissions, although the open group had significantly lower lesions. A third observational study carried out by Noura et al., ${ }^{6}$ there was an association between greater morbidity and more severe complications in the group in which the defect was 
TAMIS with No Closure of the Rectal Defect Naiderman et al. 351

Table 4 Comparative publications

\begin{tabular}{|l|l|l|l|l|l|l|}
\hline Authors & $\begin{array}{l}\text { Patients } \\
(\mathbf{n})\end{array}$ & $\begin{array}{l}\text { Global } \\
\text { morbility (\%) }\end{array}$ & Morbility (\%) & Bleeding (\%) & Infection (\%) & Reoperation (\%) \\
\hline Ramirez et al. $^{26}$ & 40 & 10 & $15(\mathrm{C}) ; 5(\mathrm{O})$ & $0(\mathrm{C}) ; 0(\mathrm{O})$ & $5(\mathrm{C}) ; 5(\mathrm{O})$ & $0(\mathrm{C}) ; 0(\mathrm{O})$ \\
\hline Hahnloser et al. $^{20}$ & 75 & 19 & $12.5(\mathrm{C}) ; 17.1(\mathrm{O})$ & $3(\mathrm{C}) ; 11(\mathrm{O})$ & $10(\mathrm{C}) ; 6(\mathrm{O})$ & $2.5(\mathrm{C}) ; 0(\mathrm{O})$ \\
\hline Noura et al. $^{6}$ & 43 & 18,6 & $33.3(\mathrm{C}) ; 1.5(\mathrm{O})$ & $23.8(\mathrm{C}) ; 0(\mathrm{O})$ & $4.6(\mathrm{C}) ; 0(\mathrm{O})$ & $19(\mathrm{C}) ; 0(\mathrm{O})$ \\
\hline Brown et al. $^{16}$ & 341 & 11,7 & $8.4(\mathrm{C}) ; 19(\mathrm{O})$ & $4.7(\mathrm{C}) ; 7.6(\mathrm{O})$ & $2.1(\mathrm{C}) ; 6.7(\mathrm{O})$ & $0.4(\mathrm{C}) ; 1.9(\mathrm{O})$ \\
\hline Lee et al. $^{19}$ & 220 & 13,6 & $12(\mathrm{C}) ; 15(\mathrm{O})$ & $9(\mathrm{C}) ; 5(\mathrm{O})$ & $5(\mathrm{C}) ; 3(\mathrm{O})$ & $3(\mathrm{C}) ; 2(\mathrm{O})$ \\
\hline
\end{tabular}

Abbreviations: C, closed defect; O, open defect.

closed. Menahem et al., ${ }^{15}$ in their meta-analysis on 503 patients, did not find significant differences in terms of global morbidity, including bleeding and infections. Likewise, the same conclusion was reached by Lee et al. ${ }^{19}$, in a posterior study (-Table 4 ).

There are important limitations in the published literature. Most publications are multicenter studies in which the perioperative management is not standardized. There are different inclusion criteria based on the height or size of the lesions, and whether the patients underwent neoadjuvant treatment or not. Patients were operated on with different techniques, different instruments and equipment are compared. In many of the reports, the decision to close the rectal wall defect or not was left to the intervening surgeon, with different levels of experience. ${ }^{15,19,20}$

In the present series, all patients underwent the same perioperative treatment and were operated on by the same surgeon. Patients submitted and not submitted to neoadjuvant treatment were included and, in no case the defect was closed, regardless of the height or size of the lesion. A harmonic scalpel was used in all interventions, and it was associated with lower postoperative bleeding compared with diathermy alone. ${ }^{36}$

The overall morbidity was of $14.2 \%$ ( 5 patients with mostly mild complications), which in line with other published series. There was only 1 (2.8\%) grade-III complication according to the Clavien-Dindo classification, the only case in the series that required re-intervention (TAMIS) due to intrahospital bleeding, and hemostasis was achieved with a harmonic scalpel.

When analyzing the patients who underwent neoadjuvant treatment, 2 out of 5 were readmitted for pain management (Clavien-Dindo II) representing a morbidity of $40 \%$ for this group. Although the series describe a higher rate of complications in patients who received chemo-radiotherapy, local resection has a specific indication being very useful and oncologically-safe in cases where there is a doubt of complete remission. ${ }^{38,39}$ In our series, it was possible to identify residual tumor in 2 patients who subsequently underwent an abdominoperineal amputation.

In patients whose defect is closed, a suture dehiscence rate of $47 \%$ has been described; this rate was of almost $60 \%$ in patients who underwent neoadjuvant treatment, in which the relationship with postoperative pain is not clear. It has been postulated that leaving the wound open could reduce this complication. ${ }^{39}$

In the present series, there were no postoperative infections which could be associated with the administration of prophylactic antibiotics in the intra- and postoperative periods, as well as no cases of contaminated closed cavity, which may occur when the defect is closed.

The type of anesthesia most commonly used for this type of surgery is general anesthesia. We used general anesthesia in the first 4 patients; then, general anesthesia plus spinal anesthesia in the next 9 , and only spinal anesthesia in the last 22 (4 patients, $11.4 \%$, next $9,25.7 \%$, last $22,62.85 \%$ ), without the need for conversion to general anesthesia in any of them. Spinal anesthesia has improved the instability of the pneumorectum and reduced the surgical field, being one of the technical difficulties of TAMIS surgery. This could be due to a greater relaxation of the rectal wall and a decrease in the collapse of it, secondary to the diaphragmatic excursion that occurs during the ventilation of positive pressure used in general anesthesia. Additionally, higher level of relaxation of the sphincter is achieved, which reduces the need for manual dilation for the introduction of the transanal device and the possibility of alteration in continence. ${ }^{40,41,43}$ Other concomitant benefits are prompt deambulation and a quicker resumption of oral intake, which results in a shorter hospital stay. ${ }^{41,42}$ This was reflected in the present series, with an operating time of $39.2 \pm 20.5$ minutes and a hospital stay of $33 \pm 28.2$ hours. $^{43}$

All patients were submitted to endoscopic controls at least one year after surgery, and there were no cases of postoperative stenosis, even with resections of 9-cm long lesions (-Figure 1). It is very difficult to close these types of defects without narrowing the rectal lumen, which does not take place when leaving the wound open and waiting for second-intention healing.

Despite performing full-thickness resections of the wall, in the present series there were no cases of perforation within the abdominal cavity, which, in other series, were observed in up to $6 \%$ of the cases. ${ }^{44,45}$ This is due to the fact that we selected patients with lesions of either the middle or lower rectum, reducing the possibility of this complication. Although mortality rates are low, they are reported in up to $2 \%$ of the cases. ${ }^{46,47}$ In the present series, there was no mortality. 

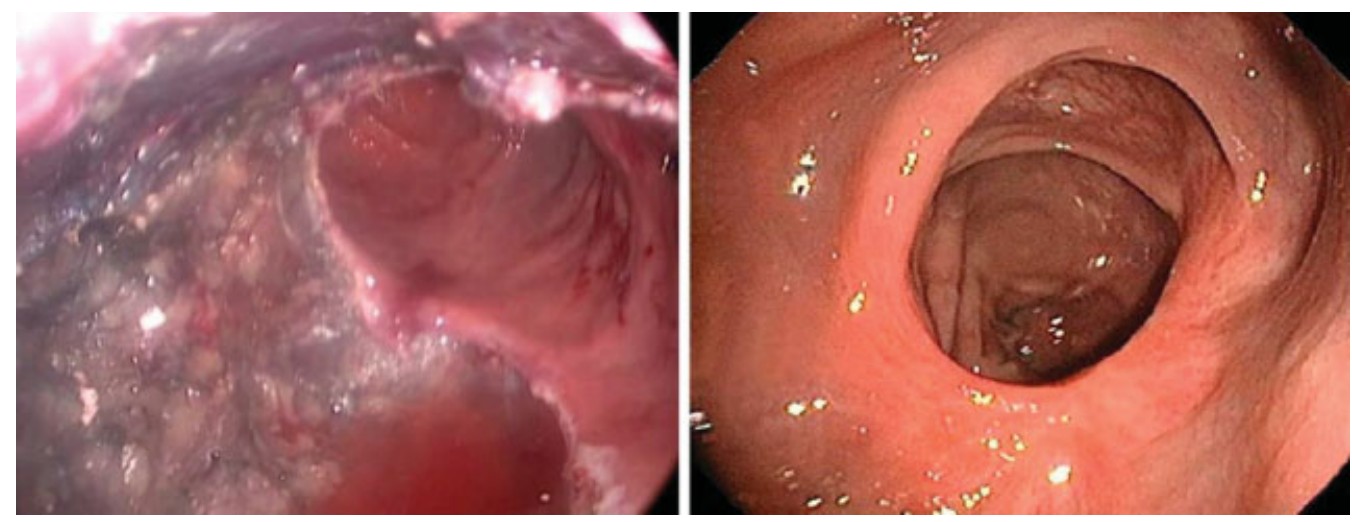

Fig. 1 Surgical wound in 9-cm lesion and endoscopic control at 6 months.

When analyzing our results and taking into account that, in most studies, no significant differences were observed between the patients in whom the surgical defect was closed and those in whom it were left open, the benefit of closing the rectal wound should be reconsidered. Regarding the latter, it is a laborious stage of the surgery, which prolongs it and presents similar rates of complications. Additionally, leaving the rectal defect open is technically less demanding and a greater number of surgeons can perform this type of intervention. Other benefits that should be highlighted are the shorter surgical time, a quick resumption of oral intake and deambulation, which means shorter periods of hospitalization. The main limitation of the present work is that, since it is a descriptive study, we are unable to make a comparison with the potential results obtained when closing the surgical defect with the same equipment, technique and surgical team. In any case, the results of the present study serve as a first step, which highlights the need for comparative studies between the different techniques to reach clearer conclusions regarding their benefits.

\section{Conclusion}

The results of the present study enable us to describe the TAMIS technique, leaving the surgical defect open in extraperitoneal rectal injuries, as a technique with good results when it comes to implementation in our population, with high feasibility and a low complication rate. Therefore, the possibility of avoiding a technically-difficult stage of surgery could be considered to make the procedure easier.

\section{What does this Article Add to the Literature?}

This work shows the feasibility of leaving the rectal defect open in all TAMIS procedures in the extraperitoneal rectum, regardless of the size and histopathology of the lesion, and whether or not neoadjuvant treatment is indicated. Effective outcomes and a low rate of complications are obtained, which enable more surgeons to incorporate the technique easily.
Conflict of Interests

The authors have no conflict of interests to declare.

\section{Acknowledgement}

We would like to thank Dr. Jorge Reales, a well-known coloproctologist, former head of the Department of Surgery at Hospital Interzonal General de Agudos "Dr. Oscar E. Alende", who was the teacher of most of the surgeons who took part in the present work. He was a pioneer in our country in the development of transanal resection techniques and his teachings have motivated the development of the present publication. Secondly, we would like to thank the teams at Centro de Estudios Digestivos, Clínica Pueyrredon, and Hospital Interzonal General de Agudos "Dr. Oscar E. Alende"; without their valuable collaboration and driving force, it would have been impossible for us to perform the surgeries and collect the data.

\section{References}

1 Lakkis Z, Manceau G, Bridoux V, et al.French Research Group of Rectal Cancer Surgery (GRECCAR) and the French National Society of Coloproctology (SNFCP) Management of rectal cancer: the 2016 French guidelines. Colorectal Dis 2017;19(02):115-122. Doi: $10.1111 /$ codi.13550

2 Monson JR, Weiser MR, Buie WD, et al; Standards Practice Task Force of the American Society of Colon and Rectal Surgeons. Practice parameters for the management of rectal cancer (revised). Dis Colon Rectum 2013;56(05):535-550. Doi: 10.1097/ DCR.0b013e31828cb66c

3 Bryant CLC, Lunniss PJ, Knowles CH, Thaha MA, Chan CLH. Anterior resection syndrome. Lancet Oncol 2012;13(09):e403-e408. Doi: 10.1016/S1470-2045(12)70236-X

4 Abdelli A, Tillou X, Alves A, Menahem B. Genito-urinary sequelae after carcinological rectal resection: What to tell patients in 2017. J Visc Surg 2017;154(02):93-104. Doi: 10.1016/j.jviscsurg. 2016.10.002

5 Morris E, Quirke P, Thomas JD, Fairley L, Cottier B, Forman D. Unacceptable variation in abdominoperineal excision rates for rectal cancer: time to intervene? Gut 2008;57(12):1690-1697. Doi: $10.1136 /$ gut.2007.137877

6 Noura S, Ohue M, Miyoshi N, Yasui M. Significance of defect closure following transanal local full-thickness excision of rectal malignant tumors. Mol Clin Oncol 2016;5(04): $449-454$ 
7 Buess G, Theiss R, Günther M, Hutterer F, Pichlmaier H. Endoscopic surgery in the rectum. Endoscopy 1985;17(01):31-35. Doi: $10.1055 / \mathrm{s}-2007-1018451$

8 Moore JS, Cataldo PA, Osler T, Hyman NH. Transanal endoscopic microsurgery is more effective than traditional transanal excision for resection of rectal masses. Dis Colon Rectum 2008;51(07): 1026-1030, discussion 1030-1031. Doi: 10.1007/s10350-0089337-x

9 Casadesus D. Surgical resection of rectal adenoma: a rapid review. World J Gastroenterol 2009;15(31):3851-3854. Doi: 10.3748/ wjg.15.3851

10 Maya A, Vorenberg A, Oviedo M, da Silva G, Wexner SD, Sands D. Learning curve for transanal endoscopic microsurgery: a singlecenter experience. Surg Endosc 2014;28(05):1407-1412. Doi: 10.1007/s00464-013-3341-5

11 Barendse RM, Dijkgraaf MG, Rolf UR, et al. Colorectal surgeons' learning curve of transanal endoscopic microsurgery. Surg Endosc 2013;27(10):3591-3602. Doi: 10.1007/s00464-0132931-6

12 Atallah S, Albert M, Debeche-Adams T, Larach S. Transanal minimally invasive surgery (TAMIS): applications beyond local excision. Tech Coloproctol 2013;17(02):239-243. Doi: 10.1007/ s10151-012-0945-z

13 Perez RO, Habr-Gama A, Lynn PB, et al. Transanal endoscopic microsurgery for residual rectal cancer (ypT0-2) following neoadjuvant chemoradiation therapy: another word of caution. Dis Colon Rectum 2013;56(01):6-13. Doi: 10.1097/DCR.0b013 e318273f56f

14 Sevá-Pereira G, Trombeta VL, Capochim Romagnolo LG. Transanal minimally invasive surgery (TAMIS) using a new disposable device: our initial experience. Tech Coloproctol 2014;18(04): 393-397. Doi: 10.1007/s10151-013-1036-5

15 Menahem B, Alves A, Morello R, Lubrano J. Should the rectal defect be closed following transanal local excision of rectal tumors? A systematic review and meta-analysis. Tech Coloproctol 2017;21 (12):929-936. Doi: 10.1007/s10151-017-1714-9

16 Brown C, Raval MJ, Phang PT, Karimuddin AA. The surgical defect after transanal endoscopic microsurgery: open versus closed management. Surg Endosc 2017;31(03):1078-1082. Doi: 10.1007/s00464-016-5067-7

17 Brown C, Hochman D, Raval MJ, et al. A multi-centre randomized controlled trial of open vs closed management of the rectal defect after transanal endoscopic microsurgery. Colorectal Dis 2019;21 (09):1025-1031. Doi: 10.1111/codi.14689

18 Wilhelm P, Storz P, Axt S, Falch C, Kirschniak A, Muller S. Use of self-retaining barbed suture for rectal wall closure in transanal endoscopic microsurgery. Tech Coloproctol 2014;18(09): 813-816. Doi: 10.1007/s10151-014-1138-8

19 Lee L, Althoff A, Edwards K, et al. Outcomes of closed versus open defects after local excision of rectal neoplasms: a multi-institutional matched análisis. Dis Colon Rectum 2018;61(02):172-178. Doi: $10.1097 /$ dcr.0000000000000962

20 Hahnloser D, Cantero R, Salgado G, Dindo D, Rega D, Delrio P. Transanal minimal invasive surgery for rectal lesions: should the defect be closed? Colorectal Dis 2015;17(05):397-402. Doi: 10.1111/codi.12866

21 Albert MR, Atallah SB, deBeche-Adams TC, Izfar S, Larach SW. Transanal minimally invasive surgery (TAMIS) for local excision of benign neoplasms and early-stage rectal cancer: efficacy and outcomes in the first 50 patients. Dis Colon Rectum 2013;56 (03):301-307. Doi: 10.4067/S0718-40262014000500019

22 Marks J, Reynolds H. Local treatment of rectal cancer (tem versus tamis versus transanal excision). Complexities in Colorectal Surgery; 2014:219-230. Doi: 10.1007/978-1-4614-9022-7_14

23 Atallah S, Albert M, Larach S. Transanal minimally invasive surgery: a giant leap forward. Surg Endosc 2010;24(09):2200-2205. Doi: 10.1007/s00464-010-0927-z
24 Morino M, Allaix ME. Transanal endoscopic microsurgery: what indications in 2013? Gastroenterol Rep (Oxf) 2013;1(02):75-84

25 Ramirez JM, Aguilella V, Gracia JA, et al. Local full-thickness excision as first line treatment for sessile rectal adenomas: long-term results. Ann Surg 2009;249(02):225-228. Doi: 10.1097/SLA.0b013e318190496f

26 Ramirez JM, Aguilella V, Arribas D, Martinez M. Transanal fullthickness excision of rectal tumours: should the defect be sutured? a randomized controlled trial. Colorectal Dis 2002;4(01): 51-55

27 Glimelius B, Tiret E, Cervantes A, Arnold DESMO Guidelines Working Group. Rectal cancer: ESMO Clinical Practice Guidelines for diagnosis, treatment and follow-up. Ann Oncol 2013;24 (Suppl 6):vi81-vi88. Doi: 10.1093/annonc/mdx224

28 Burdan F, Sudol-Szopinska I, Staroslawska E, et al. Magnetic resonance imaging and endorectal ultrasound for diagnosis of rectal lesions. Eur J Med Res 2015;20:4

29 Balyasnikova S, Brown G. Optimal Imaging Strategies for Rectal Cancer Staging and Ongoing Management. Curr Treat Options Oncol 2016;17(06):32. Doi: 10.1007/s11864-016-0403-7

30 Garcia-Aguilar J, Mellgren A, Sirivongs P, Buie D, Madoff RD, Rothenberger DA. Local excision of rectal cancer without adjuvant therapy: a word of caution. Ann Surg 2000;231(03):345-351. Doi: 10.1097/00000658-200003000-00007

31 Martin-Perez B, Andrade-Ribeiro GD, Hunter L, Atallah S. A systematic review of transanal minimally invasive surgery (TAMIS) from 2010 to 2013. Tech Coloproctol 2014;18(09): 775-788. Doi: 10.1007/s10151-014-1148-6

32 Gill S, Stetler JL, Patel A, et al. Transanal minimally invasive surgery (TAMIS): Standardizing a Reproducible Procedure. J Gastrointest Surg 2015;19:1528-1536. Doi: 10.1007/s11605-0152858-4

33 Lim SB, Seo SI, Lee JL, et al. Feasibility of transanal minimally invasive surgery for mid-rectal lesions. Surg Endosc 2012;26(11): 3127-3132. Doi: 10.1007/s00464-012-2303-7

34 Lorenz C, Nimmesgern T, Back M, Langwieler TE. Transanal single port microsurgery (TSPM) as a modified technique of transanal endoscopic microsurgery (TEM). Surg Innov 2010;17(02): 160-163. Doi: $10.1177 / 1553350610370751$

35 Ragupathi M, Haas EM. Transanal endoscopic video-assisted excision: application of single-port access. JSLS 2011;15(01): 53-58. Doi: 10.4293/108680810X12924466009005

36 Bignell MB, Ramwell A, Evans JR, Dastur N, Simson JN. Complications of transanal endoscopic microsurgery (TEMS): a prospective audit. Colorectal Dis 2010;12(7 Online):e99-e103. Doi: 10.1111/ j.1463-1318.2009.02071.x

37 Issa N, Murninkas A, Schmilovitz-Weiss H, Agbarya A, Powsner E. Transanal endoscopic microsurgery after neoadjuvant chemoradiotherapy for rectal cancer. J Laparoendosc Adv Surg Tech A 2015;25(08):617-624. Doi: 10.1089/lap.2014.0647

38 Rullier E, Rouanet P, Tuech JJ, et al. Organ preservation for rectal cancer (GRECCAR 2): a prospective, randomised, openlabel, multicentre, phase 3 trial. Lancet 2017;390(10093): 469-479

39 Perez RO, Habr-Gama A, São Julião GP, Proscurshim I, Scanavini Neto A, Gama-Rodrigues J. Transanal endoscopic microsurgery for residual rectal cancer after neoadjuvant chemoradiation therapy is associated with significant immediate pain and hospital readmission rates. Dis Colon Rectum 2011;54(05):545-551. Doi: 10.1007/DCR.0b013e3182083b84

40 Lee TG, Lee SJ. Transanal single-port microsurgery for rectal tumors: minimal invasive surgery under spinal anesthesia. Surg Endosc 2014;28(01):271-280. Doi: 10.1007/s00464-013-3184-0

41 Martin-Perez B, Andrade-Ribeiro GD, Hunter L, Atallah S. A systematic review of transanal minimally invasive surgery (TAMIS) from 2010 to 2013. Tech Coloproctol 2014;18(09): 775-788. Doi: 10.1007/s10151-014-1148-6 
354 TAMIS with No Closure of the Rectal Defect Naiderman et al.

42 Arezzo A, Cortese G, Arolfo S, et al. Transanal Endoscopic Operation under spinal anaesthesia. Br J Surg 2016;103(07):916-920

43 Cortese G, Sales G, Maiolo G, Morino M, Scanu M, Brazzi L. Effectiveness of spinal anesthesia in transanal endoscopic microsurgery: a 3-year experience. Minerva Anestesiol 2018;84(06):712-719

44 Morino M, Allaix ME, Famiglietti F, Caldart M, Arezzo A. Does peritoneal perforation affect short- and long-term outcomes after transanal endoscopic microsurgery? Surg Endosc 2013;27(01): 181-188. Doi: 10.1007/s00464-012-2418-x

45 Eyvazzadeh DJ, Lee JT, Madoff RD, Mellgren AF, Finne CO. Outcomes after transanal endoscopic microsurgery with intraperito- neal anastomosis. Dis Colon Rectum 2014;57(04):438-441. Doi: 10.1097/DCR.0000000000000063

46 Farmer KC, Wale R, Winnett J, Cunningham I, Grossberg P, Polglase A. Transanal endoscopic microsurgery: the first 50 cases. ANZ J Surg 2002;72(12):854-856. Doi: 10.1046/j.1445-2197.2002. 02590.X

47 de Graaf EJ, Doornebosch PG, Stassen LP, Debets JM, Tetteroo GW, Hop WC. Transanal endoscopic microsurgery for rectal cancer. Eur J Cancer 2002;38(07):904-910. Doi: 10.1016/S0959-8049(02) 00050-3 